\title{
Media Archaeology as the Poetics of Obsolescence
}

The notion that there was some exact instant at which the tables turned, and cinema passed into obsolescence, and thereby into art, is an appealing fiction that implies a special task for the meta-bistorian of cinema.'

\section{Preliminaries}

As the title indicates, my remarks have a somewhat retrospective slant, not least because they come out of a period of selfinterrogation and reflection on what we have been doing these past 20 or 30 years in the study of film history and media archaeology: work, for the which North Italian triangle Pordenone-Bologna-Udine has become almost as important as the triangle Florence-Venice-Genua was some 500 years ago: in each case, it brought a "renaissance" that radiated well beyond these narrow geographical confines. My own debt to especially Pordenone and Udine is immense, and I want to thank Leonardo Quaresima and the organizers for inviting me once more to the Film Forum. And to take up a phrase from Wanda Strauven's presentation: I am in some ways "hacking into my own history," but for this to make sense, I briefly have to sketch this history.

As an inveterate cinephile since the mid-1950s and party to the discussions around the dispositif in the 1970s, my turn to early cinema and pre-cinema in the 1980s was determined by three factors: dissatisfaction with the lack of historical specificity in the large scale theories that came via Paris to London and found its broad dissemination in the journal Screen; my discovery of early cinema at Pordenone (and the echoes it found in especially the New York cinematic avant-garde around the Anthology Film Archive), and thirdly, the enormous impact of Michel Foucault's The Order of Things and the Archaeology of Knowledge. Around 1988/89 I proposed the notion of "Film History as Media Archaeology" in one of the chapters of the book I edited on Early Cinema Space Frame Narrative (published in 1990)² - an idea that I developed further in a book called Cinema Futures in $1998 .^{3}$ It was an attempt to reassess what had been happening in the cinema since the advent of the video-recorder, and new the role of television as, at least in Europe, a major producer of feature films. We also examined the shifting hierarchies of sound over image, the expansion of exhibition outlets, new delivery formats and distribution platforms, as well as the proliferation of screens, together with the diversified viewing conditions of the cinema experience that this entailed. Cinema Futures brought together essays poised on the 
threshold of the digital, at a time when it was not altogether clear whether digital media constituted a radical break or merely the continuation of mechanical image making by other, i.e. electronic means, of which of course television and video were already well-established practices.

I returned to the question of media archaeology in a more programmatic essay, called "The New Film History as Media Archaeology” which was hosted by André Gaudreault's journal CiNéMAS in 2004, where I argued against positing a radical break between analogue and digital, and instead sought to use the advent of the digital for a more fundamental reflection on the basic assumptions of film history. ${ }^{4}$ In particular, I tried to make the case for what I called an "open-ended past" of the cinema, in order to counter the discussions about the "death of the cinema" that the digital had once more occasioned. I looked for overlooked inventors and entrepreneurs, for discarded and dead-end experiments, I was interested in what the past had believed as being its own future - often so different from what became the immediate actual future. Today, when both the merely imagined and the realized futures of the "pioneers" are now our distant past, some of the discarded fantasies and unfulfilled futures seem uncannily prescient and visionary, if we think of the sketches of Albert Robida or the Punch cartoon of Edison's Telephonoscope. In other words, an essential purpose of media archaeology as I conceived it was to shake up conventional chronologies and unsettle the standard periodizations, to challenge binaries such as "documentary" vs. "fiction," but above all to disprove the teleologies of "greater and greater realism," to question the assumption that the medium "film" would realize its essence through modernist reflexivity, whether phenomenological or epistemological, and to suggest that the "losers" of yesterday, in the race for "inventing" the cinema, might turn out to be the "winners" of tomorrow, and that in this sense, too, the past is never past, even where it had seemed to be lost.

\section{Media archaeology: making the past strange again}

In Amsterdam then, and largely in collaboration with Wanda Strauven and Michael Wedel, we set about examining the cinema once more, by "exploding" its parts, the way an engineering blueprint represents a composite object by giving of the parts an exploded view, i.e. of spatially distancing what in reality functions integrally and is mutually interdependent. We did a series of transversal studies (or "archaeologies") of the camera, of the screen, of projection, of the auditorium space and its relation to screen space, of synchronized sound, of movement and stillness, of luminosity and transparency, etc. I also developed what I called the underground $\mathrm{S} / \mathrm{M}$ practices of the cinematic apparatus from its beginnings, i.e. its uses for surveillance and the military, for science and medicine, as sensors and for monitoring, as storage and memory, as well as highlighting the spectators' sensory-motor schemata and their transformations from the mid-19 $19^{\text {th }}$ to the late $20^{\text {th }}$ century.

The question that came to intrigue me was: why had the cinema when it established itself in the last decade of the $19^{\text {th }}$ and the first two decades of the $20^{\text {th }}$ century put all its bets on photography (when the possibilities of electric image making and image transmission were also already known), and why had the cinema not broken with the Renaissance perspectival projection, with the rectangular framed view, and with the individualizing and subjectifying ideology that underpinned easel painting? Cubism and futurism, influenced, as we know by chronophotography, could have shown the way, but the cinema massively returned to classical modes of pictorial representation. I realized there were many reasons for this move (by no means inevitable), and also many attempts - from Eisenstein's montage theories to the perennial efforts of the various avant-gardes - to break away, but they remained by and large, minority efforts. In other words, did the cinema, right from the start, not suffer from a certain retroaction, at least in the way its history was - wrongly, as it turned out - conceived around several teleologies, which claimed that the cinema developed from primitive to mature, from fairground 
attraction to legitimate art-form, from childish prank to story-telling medium, from staged and faked enactments to greater and greater realism.

Now that we are definitely exiting the monocular perspectival era also in mainstream cinema - think Avatar and Inception, think Gravity and Interstellar, think networked narratives and mind-game films - it becomes both more obvious what could have been the alternative possibilities not taken up or actively suppressed, and it becomes less inevitable that the framed rectangle and the "window on the world," along with linear story-telling had to impose themselves with such self-evident force.

These, then, are some of the considerations that now make me reflect more critically, and "hack" into this history. Because my sense is that media archaeology has in the meantime not only become the new orthodoxy, the default value that allows some scholars to ignore the cinema altogether and move straight to the sexier bits of on-line media forms and new media practices, but it has also allowed us to rummage in film history, in early cinema and pre-cinema, as if film history was the Portobello Road flea market, where you acquire this or that useless object to decorate you mental living room with.

I won't and can't compete with Siegfried Zielinski's messianic fervor, sketching for us an an-archaeology and a global variantology that successfully rescues the past for a future yet to come..$^{5}$ But I share some of his misgivings about the temptation to appropriate the past too quickly for our own purposes by seeing everything that strikes us as remarkable in the present as having been "anticipated" a hundred or so years ago, when one of the initial impulses of media-archaeology was to make the past strange again, rather than all too familiar. Nonetheless I neither want to repudiate what has been a significant part of my own intellectual history, nor disavow those colleagues, students and conference organizers who have shared and supported these travels in time, in search of hidden pedigrees and lost paternities, and who have worked on these inventions of traditions that have helped to make film and media studies an indispensible part of the humanities and beyond.

\section{Obsolescence as meta-mechanics}

Instead, I want to explore a little more closely one of the borders of history, namely the increasing interest in the idea of obsolescence, as both a cover for an all-too-readily assumed (and consumed) nostalgia for several kinds of pre- or proto-cinematic golden ages, and as an expression of more conflicted ways of coping with the sheer presumption of novelty and the new. Obsolescence as nostalgia tends to fetishize the "first machine age" of cinema, centered on its basic apparatus (that Hollis Frampton wisely called "the last machine"), ${ }^{6}$ in a gesture that blends the superiority of hindsight with the envy of lost innocence. Yet obsolescence as a mimetic impulse towards re-enactment, recovery and redemption can open a rich field of further reflection precisely for remapping the borders of (film) history. To recapitulate:

The term, "obsolescence" has in recent years re-appeared in the vocabulary of both media historians ${ }^{7}$ and of the art world, ${ }^{8}$ as a quick look at Google entries will also confirm. ${ }^{9}$ In the process, it has significantly changed its meaning, by enlarging its semantic and evaluative range. From being a negative term within the technicisteconomic discourse of "progress through creative destruction," it became a critical term in Marxist discourse, when designers and marketing people advanced the principle of "planned" or "built-in" obsolescence, while critics of consumerism in the 1950s, such as Vance Packard, attacked such planned obsolescence as both wasteful and immoral. ${ }^{10}$

But now the meaning of obsolescence has once more shifted: it has entered the realm of the positive, signifying something like heroic resistance to relentless acceleration, and in the process has become the badge of honour of the no-longer-useful (which by itself associates the obsolete with the "disinterestedness" of the aesthetic 
impulse). ${ }^{11}$ Obsolescence can even be the rallying point for sustainability and recycling, while also making an eloquent plea for an object-oriented philosophy and a new materialism of singularity and self-sufficiency of being. ${ }^{12}$

The questions this raises are twofold: what might be the reasons for these changes in meaning and reference, and what exactly is our own speaking position, i.e. where do we film scholars stand, as we re-evaluate the obsolete as potentially the new gold standard of "authenticity" or even - to speak with Alain Badiou - as our own "fidelity to the event?" To take the second question first: no doubt, the reason we can name the concept of obsolescence and play with its meanings, is because of our awareness that with digital media we have crossed a metaphoric Rubicon, which casts in a new light everything on the other side. Just as we had to retroactively invent the word "analogue" to distinguish it from the digital, or rebrand the word "vinyl" to designate what used to be called a "record," 13 once musical recordings became compact discs and mp3 files, so we are marking with the word "obsolescence" a rift or a rupture that seems to put us in this superior position, but also in a position of belatedness. In other words, the obsolete occupies an ambiguous place, from which we may well wish to take an inner distance: either ironic or empathetic, or both. Given its previously negative connotations, obsolescence might even join those self-ascriptions, where a minority proudly refers to itself by the abusive or offensive terms the majority insinuates under its breath: the obsolete understood as the bad-ass or steam punk among the shiny media gadgets of the digital era.

As the cycles of updates, upgrades in the field of consumer electronic and software have speeded up, obsolescence necessarily connotes or implies the digital as its negative foil. This is reflected in some of its current definitions:

Obsolescence is the state of being which occurs when an object, service, or practice is no longer wanted even though it may still be in good working order. Obsolete refers to something that is already disused or discarded, or antiguated. [...] A growing industry sector is facing issues where the life cycles of products no longer fit together with life cycles of components. This [gap] is known as obsolescence, [and it] is most prevalent for electronics technology [...] However, obsolescence extends beyond electronic components to other items, such as materials, textiles, and mechanical parts. In addi tion, obsolescence has been shown to appear for software, [manufacturing] specifications, standards, processes, and soft resources, such as buman skills. ${ }^{14}$

The last part of the sentence is compelling, since it spells out the antiquatedness and includes the obsolescence of what are here called the "soft resources," i.e. human skills and by extension, human beings: a point I shall return to, since it hints at our own anxieties of not being able to keep pace with the accelerated turnover-cycles that technology and capitalism are imposing on human life-cycles. ${ }^{15}$ But first I want to suggest a slightly different context within which obsolescence has gained new currency, albeit also not without its own ambivalences and potential pitfalls. This context I want to call the need to re-invent history, and it is under this heading that I think it deserves our special attention at a conference on the "borders of the historical."

\section{The ends of history or the borders of history?}

For the past 20-odd years we have heard about the "end of history." Francis Fukuyama's essay by that title from 1989, even though commenting on the Fall of the Berlin Wall and the end of Communism of that year, was itself the tail-end of debates throughout the 1970s and 1980s about the end of the grand narratives, the end of the Enlightenment belief in progress: in short, the post-Marxist, post-modern arguments associated with the names 


\section{Thomas Elsaesser}

of Jean Francois Lyotard, Jean Baudrillard and Michel Foucault. When Baudrillard denounced "la mode retro" as fetishistic, arguing that "the cinema is fascinated by itself as a lost object as much as it (and we) are fascinated by the real as a lost referent," 16 he was speaking from a position where history (i.e. political and social change) was still considered a possibility, even as he acknowledged that "history is the lost referent." When Foucault's recast the order of things, in order to lay bare the archaeology of knowledge, its epistemes and the micro-politics that bind power to discourse, he no longer assumed a historical force, whose loss or absence one might mourn, but posited instead that the distinct epistemes followed each other more or less only by the rupture that separated them, refraining from naming the dynamics that determined the shift from one episteme to the other.

Much of media archaeology initially arose from this Foucauldian moment, casting doubt on linear film history or mono-causal accounts of the emergence of cinema. But this "turn" is also echoed several other challenges to history as a discipline that aligned facts and evidence in orderly sequences. In particular, two distinct but related concepts, namely "the archive" and "memory" came to compete with the idea of history as it had developed since the $19^{\text {th }}$ century. As revolutions, wars and other human disasters of the $20^{\text {th }}$ century presented those who came after with events whose aftermath and consequences exceeded the categories usually associated with history, both the archive and memory emerged as alternative organizing principles. Neither is subject to a strictly linear trajectory, nor are they obliged to follow the unidirectional arrow of time. Instead they have accustomed us to a spatialization of time that allows for simultaneity and co-presence of distinct moments in time and space. The spatial turn has altered our notions of causality, away from the billiard ball model, to more complex and contradictory relations of multiple causal chains, to seriality and repetition, to stochastic causality, as well as a preference bias towards associationist causal agents, all the way to the present preoccupation with contingency as the sole causal ground.

Another consequence of the spatial turn in history has been the reliance on narrative as a mainstay of historiography. In the 1970s Haydn White's Metabistory taught us that certain rhetorical and narrative tropes have been as the core of the argumentative modes that secured plausible historical explanation. No more: perhaps the days are not far off, when narrative - already under pressure from game theory - comes to be seen as only one possible, even if widely used way of ordering or organizing perceptual data, actions and events in a comprehensible and easily communicable way. Narrative has been mankind's privileged storage mode for at least 5,000 years, modelling itself on the human experience of time as succession in sequence, and thus following the logic of the "post-hoc ergo propter hoc," while taking as its dramatic arc (as well as its default value) the life cycle of beginning, middle and end. But now that archival principles increasingly compete with narratives, other storage modes and methods of access and recall may arise that reduce narrative, also with respect to history, to one special instance of how to render the past both present and intelligible.

The memory turn has also affected our view of history, especially since we tend to associate memory with trauma. After all, it is usually the catastrophes of the $20^{\text {th }}$ century, and among these, above all the Holocaust that are most often cited as the reason why we have become so preoccupied with collective and cultural memory. ${ }^{17}$ The purported objectivity of history - the account of who did what to whom, when, where and for what reasons - has proven to be inadequate as an appropriate response, so that memory - the living testimony, the subjective-affective account and the partial perspective - steps in to fill the gap or acts as a placeholder for the incomprehensible that we need to hold on to, as proof that we are still committed to seeking out the truth, even as understanding eludes us for the events that most affect us.

Yet memory and trauma are also at the forefront of our dealings with the past for reasons other than the disasters of the $20^{\text {th }}$ century. Thus, the fact that digital media have put at our disposal quantities of machine memory and archival storage space hitherto unimaginable in both depth and breadth, in both speed of access and 
ease of arrangement and manipulation, has also contributed to the crisis in history. The database and the archive: on the one hand, the freedom to create new orders of being that comes from random access, and on the other hand, the pressure to find new levels of generality and constraint - in the form of meta-data - in order to cope with the sheer quantity of information, or big data, has made memory and trauma useful concepts for giving a human face and an experiential dimension to the challenges of information overload and the deluge of data. Yet the archive, as Jacques Derrida has eloquently argued, is not a neutral repository of documents, or a Wunderkammer of collected curiosities, but imposes its own power structures and meaning making mechanism. ${ }^{18}$

Social media are the negative proof of Derrida's archive fever. They testify to our willingness to outsource our personal archive, i.e. our inner and outer lives, our daily routines and our most precious sentiments, attaching more and more of our lives to database logics, probability calculus and algorithmic preference routines which in turn inexorably eat away at history's two main functions, namely to assure us of our place and identity in the succession of generations, and to allow us to anticipate the future by learning from the past. Nowadays more often than not, history is either a risk assessment, projected backwards, or a sea of information and a set of data, ready to be collected and marshalled in support of present needs, political imperatives or national preoccupations. At the borders of history, then, lies data-mining and information-management.

\section{Media-memory as a challenge to bistory}

There is also a reason more directly pertinent to film studies and cinema history why especially memory has become such a prominent challenge to history. Our cinematic legacy, which is to say, the quantities of moving images and recorded sound, both their abundance and precarious survival, their vivid testimony and evidentiary power are forces, whose implications we are only beginning to fully reckon with.

If history takes over from memory precisely at the point where the past is no longer embodied in a living substance, but only accessible through the material traces that an event or a person have left behind, then recorded sound and moving images present history and memory with a conundrum and a paradox: for recorded sound and moving images are both more than mere traces and less than full embodiment, they have the uncanny power of conjuring up the living presence, while also remaining mere echoes and shadows of what once was. On film, the past has never really passed, so how can it become history? Instead, the ghostly para-life or afterlife of movies, whether fictional or documentary, whether whole or in bits and pieces, whether carefully crafted or taken on the fly, is by its very nature closer to what we understand by traumatic memory, understood as the sudden presence of past events that can recur or repeat themselves, with the full force of the lived instant, at once separate from us, and yet all too familiar. In other words, our present tendency to privilege memory over history, as the more authentic and truthful, and to associate memory above all with trauma, may to some extent be less due to actual historical traumata, and more a symptom of our culture's way of coping with the fact that the history of the $20^{\text {th }}$ century is also made up of the repositories of its mechanically and electronically recorded sounds and images: archives for which we are only beginning to find the sorting routines and narrative tropes that can manage their meanings and make bearable their magnitude. The call for digital humanities, and the discussions about meta-data are further symptoms: of both the challenge the filmic legacy poses and our present disarray in adequately dealing with it. ${ }^{19}$

In the confrontation with this massive material presence of images, which won't join the natural cycle of decay, since motion pictures of whatever kind are both lost to life and yet survive the death of what they display, the full resonances of the term "obsolescence" makes its reappearance, as perhaps the code word for some of the 


\section{Thomas Elsaesser}

ambiguities and contradictions that the undeadness of moving images have saddled us with. Obsolescence names the grieving and mourning, the denial and disavowal, but it also nurtures an insane hope and hubris that we might be able to bring this embalmed past back to life.

\section{Obsolescence begets scarcity, and scarcity creates value}

A good example of both the hope and the hubris but also sign of a more parasitic appropriation of the filmic legacy is the archaeological impulse that feeds the web with millions of videos on YouTube or Vimeo, effectively living off (and trying to monetarize) the accumulated capital of past generations. Although we all benefit from this cornucopia of so many past films having become instantly present, this scattering of the family silver may have long-term cultural implications even beyond the knotty problems of copyright and ownership. If media archaeology originally set out to impress upon us the otherness of the past, its singularity and strangeness, then the universal availability of so much material now requires the creation of new kinds of scarcity in order to confer "distinction," preserve "status" or generate "value." Obsolescence begets scarcity, and scarcity creates value. ${ }^{20}$

The art-world and museum spaces are the traditional environments where scarcity, tagged as uniqueness, autonomy and originality, is turned into value. It is thus not surprising that these are also the sites where obsolescence has become a major factor in the reflexive turn that the cinema has taken at the end of its first century. It will not have escaped anyone's attention that the moving image - in the form of video installations, documentaries, essay films, or more generally as the proliferation of black boxes inside the white cube - has made a dramatic entry into the contemporary art scene. Suddenly screen and projection, motion and sound are everywhere, when previously hushed silence and the stillness of immersive contemplation reigned supreme in the temples of art we call museums. Some reasons are internal to the development of modern art practice, if one accepts that for many of today's artists, a digital camera and a computer are as much primary tools of the trade as a paintbrush and canvas were a hundred years ago. Other reasons are part of a complicated trade-off between avant-garde cinema - agonizing and near death since the 1980s - and blockbuster exhibitions, Biennales, biannuals and documenta's: art has become a mass medium, exhibitions are the theme parks for the world's middle-classes, and art tourism now sustains cities like Amsterdam and Venice, Paris and Berlin, Belfast, Bilbao and Brisbane. And this means that the big brand museums - networked or franchised as they now are - have the means to commission artists to make films and videos, when such funds have long since dried up for filmmakers either trying to reach a cinema audience or find a niche on late-night television.

But why, then, do we see so many works that pay tribute to the cinema's past, and do so preferably by displaying the rattling machinery of projection almost as often as they feature the projected image itself? Why, for instance, has there been this love affair of artists with the $16 \mathrm{~mm}$ projector, repurposed or retrofitted, to show celluloid strips in a loop, or when exhibited as a piece of light sculpture, without any film at all, but reassuringly obsolete thanks to the purring sound of the gears and spools, become mechanical wind-up toys?

One answer is that there is now a general sense of ownership of the cinema on the part of the art world, manifest most clearly in the changing approach of the museums. When, starting in the mid-1990s, institutions like Tate Modern, the Pompidou Centre, or the Whitney in New York began making big claims in this respect, they usually had the institutional power, the legitimacy (and the money) to enforce these claims. The museum world has essentially "acquired" or "appropriated" the cinematic avant-garde, not only by commissioning new work, but contextualizing its display in their own terms. The career of an artist I have been following closely for more than forty years - Harun Farocki - is exemplary in this respect: he moved from being a relatively little-known 


\section{Media Archaeology as the Poetics of Obsolescence}

political filmmaker between the 1960 s to the 1980 s, to becoming an internationally acclaimed installation artist, specializing in warfare and surveillance, manual labor and monitor-controlled machines. He, too, is a media archaeologist, using found footage and industrial films, along with CCTV images and military training videogames, finding for his political concerns and contemporary themes in the gallery a public sphere that seems to have disappeared from cinema history and even media archaeology as currently practised. ${ }^{21}$

But the problem of appropriation remains, especially if we also think of how media archaeology initially was careful to give a local habitation and a name, i.e. both historical context and authorship, to the objects and practices it recovered from oblivion and neglect. The new sense of ownership of the cinema and its history claimed by museums has different priorities and a different agenda. And what about the artists themselves, many of whom now see themselves as curators, sometimes just of their own work, but also more boldly, as curators of the cinematic archive? They, too, claim ownership to the cinema, and derive from it the right of appropriation. Symptomatic for artists' cinema - the term now widely used in English for what the French call cinema d'exposition - is the recycling, re-staging or reworking of the classics, preferably the works of Alfred Hitchcock: Douglas Gordon's 24 Hour Psycbo, Matthias Müller and Christoph Girardet's The Pboenix Tapes, Johan Grimonprez' Looking for Alfred - to name only three out of a dozen that come to mind. ${ }^{22}$

This new sense of ownership of the cinema by the museum, by artists and art spaces is not altogether unconnected with curious conjuncture of the forever foretold "death of cinema" and an anniversary. It was as if the centenary of the Lumière Brothers invention in 1995 became the ideal occasion to praise the cinema in order to better bury it. The success of a number of ambitious, large scale exhibitions, such as Hall of Mirrors at MoCA in Los Angeles, Spellbound at the Hayward Gallery in London, Into the Light at the Whitney in New York, XScreen at MUMOK in Vienna, Le Mouvement des Images at the Centre Pompidou in Paris, or The Cinema Effect: Illusion, Reality and the Moving Image at the Hirshhorn Gallery at the Smithsonian in Washington, helped to promote the notion that the proper place for the history of the cinema - and not just avant-garde cinema - is now the curated exhibition in the museum:

In the age of digital convergence, film is increasingly becoming a touchstone for new media and video art - no longer as antipode to these media (themselves divergent), but as constructed archetype for all moving images. Whereas earlier surveys bave posited film as metaphor or have emphasized sampling and mimicry, the Hirshborn's two-part endeavor focuses on cinema's cognitive effects. The first instalment explores the ways time-based media transport us to dreamlike states; the second, their ability to construct new realities. Forty works made between 1963 and 2006 will be contributed by nearly as many artists. The roster suggests we can expect everything from the sumptuous qualities of celluloid (Tacita Dean) to interpellation into the cinematic apparatus (Anthony McCall) to surreal projected video (Paul Chan). ${ }^{23}$

\section{The museum: a politics of obsolescence}

The Hirshhorn statement confirms a dictum by Boris Groys, to the effect that today art is not made by artists, but by curators, because in order to decide what is art, you first have to be in control of the space where it appears; second, of the institution that guarantees its authenticity, and third, of the discourses that legitimate it. ${ }^{24}$ This seems to be true of the cinematic archive, too, and what I call the "politics of obsolescence" here works entirely in favour of the museum, in the sense that it constitutes a kind of takeover bid, where it is not yet clear, whether it is a hostile or friendly take-over bid, leaving it an open question whether the museum (popularity) or the movies (status) that benefit most from their mutual re-alignment.

And yet, an undeniable fascination with obsolescence also stands behind the new cinephilia: one that no longer 
merely venerates the cinema d'auteur, but also no longer shuns the Hollywood genre film; one that makes little distinctions between high culture and popular culture: it happily raids the icebox, and in the process, it makes films anonymous and turns them into fragments. It celebrates the cinema in the form of found footage compilations, using home movies (Peter Forgacs), industrial films (Gustav Deutsch), medical films, pornography, in short, it poeticises all those areas where the moving image has been used to record and document processes, events and actions. And artists are often welcomed and invited by the film archives themselves, because they are seen to add value to holdings that have lain dormant in vaults or storage facilities all over the world, for which no uses could as yet be found. Artists' sense of ownership means that sometimes they forget or ignore prior authorship or provenance, sometimes they deliberately strip context and sometimes they obfuscate the origins of the material in question, so as to present their re-working and re-staging as a surreal collage of fresh fragment or as the walk-in installation of an uncannily familiar space. The black box then also becomes a black box in the technical sense, as a space within which anything is possible, where input and output are not predetermined. ${ }^{25}$

At the other end of the spectrum, the collage and compilation can produce its own kind of apotheosis, as with Christian Marclay's The Clock, which has raised the stakes considerably for anyone dreaming of making a cinephile "found footage film," at once proving and disproving that film history's undiscovered riches, are lying right there at the surface, in the myriad of objects, details, sounds, gestures and textures, by working - indeed labouring - on the this film history's "optical unconscious." For it is with works like T'be Clock (and to some extent with the films of Matthias Müller or Gustav Deutsch) that a "poetics of obsolescence" encounters - and counters - the art world's "politics of obsolescence." Poetics is a slippery term, situated as it is between critical theory and self-imposed creative constraints, between media archaeology and free-form improvisation, but by "poetics of obsolescence" I am not only referring to the already mentioned totemic use of $16 \mathrm{~mm}$ celluloid by a Tacita Dean, the regular clacking of a carrousel slide projector of a Nan Goldin or a James Coleman installation, or the recurring typewriters in William Kentridge and Rodney Graham.

These are the outward signs, the trademarks, as it were, by which artists flag the value they attach to such a mise-en-scene of obsolescence. In many ways, obsolescence has become the overarching concept, under whose broad etymological expanse and varied figurations the appropriation of the cinema as shared heritage, but also its valorization as the artists' privileged domain of (self-)reflexivity and re-assessment proceeds most effectively, forming a slender bridge between an institutional trafficking with nostalgia and retro-fashion, and the artists tentatively optimistic re-examination of the cinema - a medium that art history has assiduously ignored for the best part of the $20^{\text {th }}$ century. What is crucial, it seems to me, is that the poetics of obsolescence announces a different relation between present, past and future, not just by acts of creative anachronism, but also by treating technological obsolescence like an anchor, cast into the churning sea of an uncertain future, brought on not only by the episteme of the digital, but also by the globalization of art and museum practice. In this reflexiveretroactive turn, artists enact something of deeper significance, also for the rest of us. The present moment, cognizant of its (social) stasis and (political) paralysis, can look at the past's obsolescence as if into a mirror of its own fate, and not only take comfort from it, but by actively preserving these obsolete objects and treasure their uselessness, we protect, love and redeem ourselves, in a proxy gesture of half-acknowledged narcissism.

The big museums that are now appropriating the cinema's rich history and varied legacy, are seizing the opportunity to service our generalized nostalgia and longing for lost innocence, by giving it the rationale of guarding the archive and preserving the heritage. In its shadow and under its patronage, film-, video- and digital artists can thus practice their own poetics: proactively and prophylactically deploying obsolete technologies, in order to counter the ephemerality of work that increasingly depends for its performance and presence on audio-visual hardware or digital software. Such work demands that future curators turn themselves into archivists: they 
need to catalogue, store and study not only the work as such, but also the technologies required to put it once more on display. These supporting technologies - hardware like tape-recorders or overhead projectors, software like disk-formats or operating systems - may yet become the most valued part of the artwork, in a kind of master-slave dialectical reversal, where the obsolete is respected for its self-oblivion and resistant materiality, for what Roland Barthes called "the obtuse meaning," as an antidote against too much signification, too much intentionality and meaning. ${ }^{26}$ Thus, it is not only the case that trash becomes treasure, in a value cycle where obsolescence has always been an integral part: discarded objects may be rubbish, but if they are kept long enough, they become collectibles, and as collectibles, if only they become scarce enough, they advance to being classics, and even - given the proper discourse - art. ${ }^{27}$

\section{The artist: a poetics of obsolescence}

Obsolescence, understood as the survival of a witness to past "newness" while renouncing past utility, can therefore also harbour utopian aspirations, and even be the vehicle of lost promises and unfulfilled potential. This positive view of the poetics of obsolescence we can trace back to Walter Benjamin and his reflections on the surrealist object. ${ }^{28}$ Freed from utility and market value, both the hand-crafted implement and the industrially made commodity can reveal unexpected beauty and deploy a potent charm: out of the transition from usevalue to display value, and from cult object to the disenchantment of the world, Benjamin derived not only an exalted view of the collector, ${ }^{29}$ but also a whole theory of the origins of art. Extending his thinking, one can say that when reclaiming the discarded, preserving the ephemeral and redeeming the newly useless, we are also paying tribute to sustainability and the ethics of recycling, even if only in the form of the symbolic act that is the work of art, or the scholarly discourse of the media-archaeologist.

At this point it is worth recalling Marshall McLuhan's tetrad of media effects: "What does the medium enhance and amplify? What does the medium discard and make obsolete? What does the medium reverse or how does it flip when pushed? What does the medium retrieve that had been discarded?"30 With only minor adjustments - for instance, by inverting the direction of McLuhan's causal arc from old to new, and allowing for the discovery of the new in the old medium, and not only the effects of the new on the old medium - the current interactions between the art world and the cinematic archive are holding all these parts of McLuhan's tetrad in suspended animation: whether we think of art historian Rosalind Krauss advocating the post-medium condition as the "new medium specificity" in her effort to rescue modernism, ${ }^{31}$ whether we take the museum space as the critical site at the intersection of enbancement (value creation) and retrieval (public access), or whether we study artists like Tacita Dean, Rodney Graham, or William Kentridge, pushing the old medium to the point where it flips, in the full awareness that the digital has effected a kind of figure-ground reversal, with the old emerging as the new "new." 32

At the heart of many of these processes and phenomena is our own deeply paradoxical cultural moment, where to be retro is to be novel, where "going vintage" is "avant-garde." The wider implications, however, suggest that the poetics of obsolescence and the idea of progress (or what is left of it) have become the recto and verso of each other: through obsolescence we negatively conjure up the ghost of progress past. In this sense, one of the strategic uses of obsolescence as a critical concept can be found in the fact that, being a term that inevitably associates both capitalism and technology, it is of special interest in the context of both the art world and the audio-visual media, both old and new, because it implicitly acknowledges that today there is no art outside capitalism and technology. Both our historical and critical thinking needs to take account of this fact, and as film scholars and media archivists, this insight comes more easily to us than it does to art historians and curators. 
Obsolescence, then, would hint at a political dimension, since the contemporary art world seems to have succumbed to the dialectics of (technological) innovation and (capitalist) obsolescence, rather than remaining the bulwark against creative destruction, impervious to the cycles of fashion that it claims to be. Yet how could it be otherwise? If capitalism is indeed the most revolutionary, which is to say, the most disruptive force in the contemporary world, it is at the same time, the untranscendable horizon of our thinking and being. This not only means that there is no outside to the inside, which renders any critical stance that much more difficult to protect from being co-opted, but it gives obsolescence a new kind of self-contradictory dignity: it is on the inside, but it makes its stand against the inside, and thus speaks a paradoxical truth of which it is itself the embodiment. The fact that obsolescence can be the new "new" is therefore not only a sign that the fashion system now fully pervades cultural production (as Boris Groys would have it); it also confirms the point with which I began: namely that we have lost our faith in progress, and thus our belief in history.

Obsolescence is "history at a standstill," to vary Benjamin's famous aphorism about the allegorical image. But by arresting history, suspending time and reversing its flow, obsolescence can be a moment of reassessment as well as of renewal, which is why I want to insist that obsolescence implies a special relation of past to present that no longer follows the direct linearity of cause and effect, but takes the form of a loop, where the present rediscovers a certain past, to which it then attributes the power to shape aspects of the future that are now our present. Remaining within Benjamin's frame of reference, we can cite his messianic conception of Jetztzeit or Now-time, and say that "the past is always formed in and by the present. It comes into discourse analeptically in relation to a present, and since it is read from the standpoint of the present, it is proleptic as well, in that it forms "the time of the now'." 33 This analeptic-proleptic relationship I call the "loop of belatedness," which is to say, we retroactively discover the past to have been prescient and prophetic, as seen from the point of view of some special problem or urgent concern in the here and now. Much of our work as media archaeologists is, for good or ill, caught in this loop of belatedness, where we retroactively assign or attribute uncanny agency to a moment or a figure from the past that suddenly speaks to us in a special way.

As media archaeologists we have often favoured the archaeology of the cinema over the history of films. Much of the new film history, for instance, was proud of doing its work without actually watching any films, and we pitied those who were laboriously extrapolating social history or ideology on the basis of some more or less obscure hermeneutic process. If however, I am right in saying that film, by its peculiar ontology of undeadness and not-aliveness effectively suspends or undermines the very possibility of a history as traditionally understood, our move to archaeology is not going to help us forever. The gap between film on one side, and the cinema on the other is bound to open up again, if it has not done so already: for what exactly lurks at the borders of the historical? If we go to contemporary system theory, for instance to Niklas Luhmann, we learn that history does not exist, indeed the very idea of the past is only a prosthetic fiction we have invented in order to map repetition and difference, to which we add causality, in order not be swallowed up by the inexorable contingency of our lived reality. If we go to quantum physics, cause and effect either do not exist or are taken to be reversible: physicists like Stephen Hawking and Thomas Hertog propose a "top down cosmology" that views the universe as having begun in every possible way, with the most probable pasts being determined right now. ${ }^{34}$ Thus, it would seem that the loop of belatedness, which I associate with the poetics of obsolescence, is neither as tautological nor as retrograde as it might appear. For at the borders of the historical lies also our mortality, and the irreversibility of the arrow of time for all living beings. "Films" (in the digital age), with their apparent suspension of this irreversibility would seem to mock us with the promise of some sort of immortality, whereas "cinema" (envisaged once more as the dark space, the cave, the camera obscura) preserves all the terrors of mortality, and becomes the very epitome of our precariousness as individual subjects and as a species. This is perhaps why Raymond Bellour wants to call "cinema" only that which insists on the irreversibility of the pro- 
jected image. ${ }^{35}$ But it also suggests that the gap that has opened up between the ontology of "film" and the archaeology of "cinema" is an important one, indeed an essential one: it helps us keep the faith in the potential of a future, even if as a species, it is not sure we have one, and reconciles us to the knowledge that as a blip in the universe, we never had a past. Media archaeology, understood as part of a poetics of obsolescence, would be the perfect balancing act between both these possibilities, where the future of the cinema renews itself whenever we experience its obsolescence as a promise. It is, as Hollis Frampton indicates, "an appealing fiction."

\section{Notes}

${ }^{1}$ Hollis Frampton, "For a Metahistory of Film: Commonplace Notes and Hypotheses," in Artforum, vol. 10 , no. 1,1971 , p. 35 .

2 Thomas Elsaesser, Early Cinema. From Linear History to Mass Media Archaeology, in Id. (ed.), Early Cinema. Space Frame Narrative, BFI, London 1990, pp. 1-8.

${ }^{3}$ Thomas Elsaesser, Kay Hoffmann (eds.), Cinema Futures: Cain Abel or Cable, Amsterdam University Press, Amsterdam 1998.

${ }^{4}$ Thomas Elsaesser, "The New Film History as Media Archaeology," in CiNéMAS : revue d'études cinématographiques, vol. 14, nos. 2-3, 2004, pp. 71-117.

${ }^{5}$ Siegfried Zielinski, Deep Time of the Media: Toward an Archaeology of Seeing and Hearing by Tecbnical Means, MIT Press, Cambridge 2006.

${ }^{6}$ Hollis Frampton, "For a Metahistory of Film: Commonplace Notes and Hypotheses," cit., p. 35.

${ }^{7}$ In 2013 the University of Göttingen hosted a major conference entitled Cultures of Obsolescence (http://www.uni-goettingen.de/de/419609.html).

"See October 100: Obsolescence: A Special Issue, no. 100, 2002.

9 Among the googled terms were "digital obsolescence," "media obsolescence," "obsolescence hardware and media," "dead media - obsolescence and redundancy," "dead media walking? Obsolete communications systems," etc.

${ }^{10}$ Vance Packard, The Waste-Makers, Vance Packard Inc., Philadelphia 1960.

${ }^{11}$ In May 2014 the punk band GRYSCL released an album called Finding Comfort in Obsolescence (http://brokenworldmedia.bandcamp.com/album/finding-comfort-in-obsolescence).

12 See Steven J. Jackson, Laewoo Kang, "Breakdown, Obsolescence and Reuse: HCI and the Art of Repair," http://sjackson.infosci.cornell.edu/Jackson\&Kang_BreakdownObsolescenceReuse \% $28 \mathrm{CH}$ I2014\%29.pdf.

${ }^{13}$ Originally vinyl referred to vinyl chloride, an industrial plastic, which derives its mellifluous name from wine, because of its remote kinship with ethyl alcohol. As a retronym, "vinyl" interestingly does not name the process (recording) or product (sound), but refers to their material substratum, thus signalling a shift in affective attention.

${ }^{14}$ http://en.wikipedia.org/wiki/Obsolescence.

${ }^{15}$ Acceleration has become another ambiguous word in this context, connoting on the one hand the bad object, against which "slow" has been valorized, while on the other hand, the Acceleration Manifesto claims that only the need for speed will ensure our future.

${ }^{16}$ Jean Baudrillard, History: A Retro Scenario, in Id., Simulacra and Simulation, University of Michigan Press, Ann Arbor 1994, pp. 43-48, p. 47. 
17 See for instance Michael S. Roth, Memory, Trauma, and History: Essays on Living with the Past, Columbia University Press, New York 2011.

${ }^{18}$ Jacques Derrida, Archive Fever: A Freudian Impression, University of Chicago Press, Chicago 1996.

19) Scholars like Franco Moretti, Alan Liu and Lev Manovich have been at the forefront of the debate around the "perils and promises" of digital humanities. See Alan Lui's blog (http://liu.english.ucsb. edu/is-digital-humanities-a-field-an-answer-from-the-point-of-view-of-language), Scott Kleiman (http://scottkleinman.net/blog/2014/02/24/digital-humanities-as-gamified-scholarship/) or the critical notes sounded by Adam Kirsch (http://www.newrepublic.com/article/117428/limits-digital-humanities-adam-kirsch).

${ }^{20}$ In this context, a remark by Tacita Dean is instructive: "obsolescence hounds my working life. Laboratories close down. Shops no longer stock spools [...]. And so obsolescence ends in an underworld of people dealing from dark rooms and flea-market stalls, until enough time passes, so that whatever it was that was obsolete, has now become rare. And rare no longer holds my attention." October, no. 100, 2002, p. 26

21 See the commemorative issue of e-flux on Harun Farocki, October 2014 (http://www.eflux.com/announcements/issue-59-harun-farocki-out-now/).

${ }^{22}$ For a more extended analysis of Hitchcock in the museum, see Thomas Elsaesser, Casting Around: Hitchcock's Absence, in Johan Grimonprez, Looking for Alfred: The Hitchcock Castings, Hatje Cantz, Ostfieldern 2007, pp. 139-161.

${ }^{23}$ See "The Cinema Effect: Illusion, Reality, and the Moving Image," Hirshhorn Museum and Sculpture Garden, Washington, DC. Curated by Kerry Brougher, Anne Ellegood, Kelly Gordon, and Kristen Hileman.

${ }^{24}$ Boris Groys, "The Art Exhibition as Model of a New World Order," in Open 16: The Art Biennial as a Global Phenomenon. Strategies in Neopolitical Times, NAI Publications, Rotterdam 2009, pp. 56-65.

${ }^{25}$ On found footage films, see the essays collected in Cecilia Hausheer, Christoph Settele (eds.), Found Footage Film, VIPER/zyklop, Luzem 1992, and Catherine Russell, Experimental Ethnography: The Work of Film in the Age of Video, Duke University Press, Durham 1999.

${ }^{26}$ Roland Barthes, The Third Meaning: Research Notes on some Eisenstein Stills, in Stephen Heath (ed.), Image Music Text, Hill \& Wang, New York 1977, pp. 49-68.

27 On value cycles, see Michael Thompson, Rubbish Theory: The Creation and Destruction of Value, Oxford University Press, Oxford 1979.

${ }^{28}$ Walter Benjamin, "Surrealism: The Last Snapshot of the European Intelligentsia," in New Left Review, no. 108, 1978, pp. 47-56.

${ }^{29}$ On collecting, see Walter Benjamin, Unpacking my Library, in Hannah Arendt (ed.), Illuminations, Schocken Books, New York 1969, pp. 59-67.

${ }^{30}$ Marshall McLuhan, The Tetrad of Media Effect, in Id., Eric McLuhan, Laws of Media: The New Science, University of Toronto Press, Toronto 1988.

${ }^{31}$ Rosalind Kraus, A Voyage on the North Sea: Art in the Age of the PostMedium Condition, Thames \& Hudson, London 2000.

32 "Everything that excites me no longer functions in its own time. [...] I court anachronism - things that were once futuristic but are now out of date - and I wonder if the objects and buildings I seek were ever, in fact, content in their own time, as if obsolescence was invited at their conception." Tacita Dean, Octoher, cit., p. 26.

${ }^{33}$ Jeremy Tamblin, Becoming Posthumous: Life and Death in Literary and Cultural Studies, Edinburgh University Press, Edinburgh 2001, p. 4. 


\section{Media Archacology as the Poetics of Obsolescence}

it "Instead of looking for some fundamental set of initial physical laws under which our Universe unfolded, it starts 'at the top', with what we see today, and works backwards to see what the initial set of possibilities might have been. In effect, says Hertog, the present 'selects' the past [...]. If we start from where we are now, it is obvious that the current Universe must 'select' those histories that lead to these conditions." Philip Ball, "Hawving rewrites history... backwards," in Nature Netes, 2006, http://www.bioedonline.org/news/nature-news/hawking-rewrites-history-backwards.

35 "La projection vécue d'un film en salle, dans le noir; le temps prescrit d'une séance plus ou inoins collective, est devenue et reste la condition d'une expérience unique de perception et de mémoire, définissant son spectateur et que toute situation autre de vision altère plus ou moins. Et cela seul vaut d'être appelé 'cinéma'." Raymond Bellour, La Querelle des dispositifs. Cinćma, installations, exposilioms, P.O.L., Paris 2012, p. 14. 